\title{
Organização e narração de histórias por escolares em desenvolvimento típico de linguagem e com Distúrbio Específico de Linguagem (DEL)
}

\author{
Ana Carolina de Paiva Bento ${ }^{1}$
}

Bento ACP. Organização e narração de histórias por escolares em desenvolvimento típico de linguagem e com Distúrbio Específico de Linguagem (DEL) [dissertação]. São Paulo: Faculdade de Medicina, Universidade de São Paulo; 2009. 141f.

As habilidades narrativas podem fornecer ricas informações sobre as competências linguísticas, cognitivas e sociais das crianças com desenvolvimento típico e com Distúrbio Específico de Linguagem (DEL). Os objetivos dessa dissertação foram caracterizar a ordenação temporal de figuras e a narração de histórias por escolares em desenvolvimento típico de linguagem (DTL) e com DEL. Participaram deste estudo dois grupos de sujeitos, com faixa etária de sete a dez anos: o Grupo Controle (GC), sem alterações de linguagem, composto por 60 sujeitos, e o Grupo Pesquisa (GP), com diagnóstico de DEL, composto por 20 sujeitos. Para eliciar as narrativas foi utilizada uma série de 15 histórias, representadas por figuras, compostas por quatro cenas cada. Essas sequências foram criadas e classificadas em mecânicas, comportamentais e intencionais, segundo as relações envolvidas entre os personagens. Os dados foram transcritos e analisados conforme o tipo de discurso (Descritivo, Causal e Intencional) e, além disso, foi pontuado o tipo de organização das figuras realizadas pelas crianças. Esta dissertação foi dividida em dois estudos. Os resultados do Estudo I indicaram que a capacidade de ordenação temporal de figuras já está presente em escolares em DTL aos sete anos. Com o aumento da idade os escolares em DTL diminuem o uso do tipo de discurso descritivo e aumentam o uso do discurso intencional. Além disso, houve aumento do uso dos discursos causal e o intencional com o aumento da complexidade das sequências fornecidas. O Estudo II indicou que não houve diferenças entre os discursos nas faixas etárias estudadas para o grupo com DEL. Os grupos se diferenciaram quanto à ordenação temporal e quanto ao tipo de discurso. Os escolares com DEL apresentaram discurso menos elaborado (descritivo), enquanto o grupo em DTL apresentou discurso mais elaborado (causal). As diferenças observadas entre as narrativas produzidas por escolares em DTL e com DEL ressaltaram as dificuldades desta população na utilização da língua, ou seja, nas habilidades linguísticas necessárias para narração de histórias.

Dissertação apresentada à Faculdade de Medicina da Universidade de São Paulo para obtenção do título de Mestre em Ciências da Reabilitação Humana - Área de Concentração Comunicação Humana, sob orientação da Profa. Dra. Debora Maria Befi-Lopes.

Auxílio financeiro: Fundação de Amparo à Pesquisa do Estado de São Paulo (FAPESP), processo n ${ }^{\circ} 07 / 51928-2$.

(1) Pós-graduanda (Doutorado) do Programa de Pós-Graduação em Ciências da Reabilitação Humana - Área de concentração Comunicação Humana da Faculdade de Medicina da Universidade de São Paulo - USP - São Paulo (SP), Brasil.

Endereço para correspondência: Ana Carolina de Paiva Bento. R. Cipotanea, 51, Cidade Universitária, São Paulo (SP), Brasil, CEP: 05360-160. E-mail: carolbento@usp.br 